Department of

Radiation Hygiene,

Hygienic and

Epidemiology

Inspection, Ministry of

Health, Sofia-

Bouchovo 1830,

Bulgaria

M A Michaylov

Laboratory of

Dosimetry and

Radiation Protection,

Faculty of Physics,

Sofia University, 5

James Boucher

Boulevard, Sofia 1126

Bulgaria

D S Pressyanov

Department of Medical

Informatics and

Biostatistics, High

Medical Institute, 8

Belo More Street, Sofia

1204, Bulgaria

K B Kalinov

Correspondence to:

Dr D S Pressyanov,

Laboratory of Dosimetry and

Radiation Protection, Faculty

of Physics, Sofia University,

James Boucher Boulevard

Sofia 1126 Bulgaria

Accepted 29 September 1994

\title{
Bronchial dysplasia induced by radiation in miners exposed to ${ }^{222} \mathrm{Rn}$ progeny
}

\author{
M A Michaylov, D S Pressyanov, K B Kalinov
}

\begin{abstract}
Objectives-To investigate whether sputum cytology can be used to monitor epithelial cell changes in groups at high risk of lung cancer from exposure to radiation.

Methods-Dysplasia of bronchial cells was investigated by means of sputum cytology in a group of 434 underground miners. 100 of them were not exposed, and 334 were exposed to ${ }^{222} \mathbf{R n}$ progeny at cumulative exposures $<450$ working level months.

Results-The frequency of dysplasia in
\end{abstract}

the exposed group was significantly higher than that in the not exposed group $(P<0.0001)$, and an exposure-response relation was found. This relation was different for smokers and non-smokers.

Conclusions-Possibly the frequencies of dysplasia could be used to assess past exposures of groups of miners. This approach could be applied to cases where data on radiation monitoring are not available or are very scarce.

(Occup Environ Med 1995;52:82-85)

Keywords: bronchial dysplasia; radiation; miners; radon

Assessment of the risk of developing lung cancer as a result of inhalation of $\mathrm{Rn}$ daughters is now considered to be an important problem in occupational and environmental medicine. Recently, an increased mortality in miners exposed to low doses of $R \mathbf{n}$ progeny has been reported. ${ }^{12}$ Similar risks may be expected for a proportion of the total nonmining population, as a result of exposure to $\mathbf{R n}$ indoors.

The development of bronchogenic cancer involves progressive changes in the bronchial epithelium, from cell metaplasia to malignant transformation. ${ }^{4}$ Smoking, toxic inhalants, and acute or chronic pulmonary inflammatory diseases contribute to occurrence and progress of squamous metaplasia. ${ }^{5-7}$ The stages that precede the development of carcinoma are reversible in a proportion of affected people, especially if smoking or the exposure to toxic inhalants stops ${ }^{6}$ or with treatment of the inflammatory process. ${ }^{7}$ Usually lung cancer develops only in a small proportion of the cases of epithelial cell transformations. The examination of exfoliated metaplastic cells, found in the sputum, has shown that cell transformation occurs in the bronchial epithelium long before the development of clinical symptoms. These findings have stimulated interest in sputum cytology as a method for monitoring high risk groups and prevention of lung cancer. ${ }^{8}$

We present the results of sputum cytology in a group of 434 underground miners (334 exposed and 100 not exposed to $R n$ progeny). The frequency of appearance of atypical cells (to the level of notable dysplasia, figure) in sputum specimens is significantly higher for the exposed group than for the controls. This frequency follows an exposure response 
relation that has been found to be different in smokers and non-smokers.

The present findings suggest that the information about the proportion of miners with abnormal cells in their sputum samples, could be used as an indicator of the exposure conditions in the past, if retrospective information about levels of radiation is not available.

\section{Materials and methods COHORT}

The study was carried out on a cohort of active miners who still worked underground, selected at random from the workers in five uranium and six metal mines in Bulgaria. The dust and silica concentrations in each of these mines were similar, but concentrations of $R n$ and $R n$ progeny differed significantly. In one of the metal mines, $R \mathbf{n}$ gas was virtually absent and the miners there were used as controls. The exposure to other toxic gases (diesel exhaust, explosion gases) is similar in all mines.

The miners were classified into three categories of smokers: the smokers group included only people who smoked $>10$ cigarettes/day for at least five years (the overall distribution in this group was: $0 \cdot 5-1$ pack/day $21 \%, 1$ pack $62 \%, 1-2$ packs $15 \%$, and $>2$ packs $2 \%$ ). The group of non-smokers included people who had never smoked. Ex-smokers and moderate smokers who were exposed to $R n$ were considered as a third group (there were no ex and moderate smokers among controls).

In all the uranium mines and in three of the metal mines the data from long term monitoring of radiation were available. The 233 miners (smokers and non-smokers) from these mines were defined as group A. For each of them individual exposure was determined. Three exposure categories were selected. The lowest category was of 0-50 working level months (WLM). (The WLM is a unit of cumulative exposure defined as $1.3 \times 10^{5} \mathrm{MeVl}^{-1}$ of the potential $a$ energy concentration of $\mathrm{Rn}$ daughters in air endured for 170 hours.) A proportion of the total non-mining population may be exposed to these low levels ( $\mathrm{Rn}$ indoors). The second category was of 50-150 WLM. This was the group of high occupational exposure. The third group was of exposures $>150$ WLM. With the limit of 5 WLM/year, as recommended by the International Commission on Radiological Protection, ${ }^{9}$ the cumulative exposure, for 30 years of work, should not exceed 150 WLM. Therefore, the group of exposures above 150 WLM, is representative for overexposed people.

In the remaining two metal mines, $R \mathbf{n}$ progeny have been measured since 1991 . The results have shown a substantial presence of $\mathrm{Rn}$ progeny in the atmospheres of the mines, but the real past exposures could not be determined directly. Their range was estimated by extrapolation with the assumption that ventilation during the past 15-20 years had not changed dramatically. The miners (smokers and non-smokers) in these mines were defined as group B. The ex and moderate smokers were defined as group C. The results for groups B and C were interpreted in view of semiquantitative support from the findings obtained for group A and controls. Table 1 shows a detailed description of all the groups.

\section{CYTOLOGY}

Sputum samples were collected by direct expectoration in the early morning. From each sputum sample at least three specimens were prepared with conventional techniques described elsewhere. ${ }^{1011}$ Different numbers were attached to the specimens, and under these they were further analysed for metaplasia with a transmitted light microscope.

A specimen was classified as having notable dysplasia, if the metaplastic cells vary in size and shape, the nucleus is enlarged and hyperchromatic, the nuclear to cytoplasmic ratio is increased considerably, and obvious pleomorphism or dyscariosis are present. The figure is typical of this stage of squamous metaplasia. These criteria of dysplasia support the definition given by Risse et $a l,{ }^{7}$ and the earlier classification of Fulmer et al. ${ }^{12}$

When a specimen was moderately atypical, suggestive but not conclusive of notable dysplasia, the sputum was resampled at six to 12 months. If the new specimen could not be reliably classified as dysplasia, or if the sputum sample could not be repeated, the case was excluded from further analysis (only five people were excluded because of this).

\section{STATISTICAL METHODS}

A retrospective cohort study was performed with data from group A (exposed) and controls (not exposed). ${ }^{13}$ The risk of dysplasia in relation to exposure to $\mathrm{Rn}$ progeny, smoking, and underground work experience was studied by logistic regression analysis. ${ }^{14}$ The determination of the $95 \%$ confidence intervals ( $95 \%$ CIs) was based on the likelihood ratio criterion. Levels of significance $(\mathrm{P})$ and $\chi^{2}$ were determined by the likelihood $\chi^{2}$ method. For multiple comparisons Kruscall-Wallis non-parametric analysis of variance was used. The data were analysed by the package SPSS/PC+, version $4 \cdot 01$.

\section{LUNG DISEASES}

About $46 \%$ of non-smokers and $62 \%$ of smokers in our cohort showed some degree of chronic inflammatory lung disorders. The higher frequency for smokers was significant $\left(\chi^{2}=8.86, P=0.003\right)$, but the differences between exposed and not exposed groups, considered separately for smokers and nonsmokers, were not significant.

After the end of this study one person from group A (a 40 year old with 18 years of work experience, exposure of 316 WLM and a smoker of one pack/day for 20 years) developed bronchial carcinoma (further confirmed by necropsy). He died 10 months after the first clinical symptoms. His last sputum sample was taken seven months before the first symptoms. The record showed that chronic bronchitis and severe dysplasia had been diagnosed, but without indications of carcinoma. There is no information on other lung cancers 
Table 1 Description of the groups of miners

\begin{tabular}{lllll}
\hline & $\begin{array}{l}\text { Group } A \\
(n=233)\end{array}$ & $\begin{array}{l}\text { Group } B \\
(n=79)\end{array}$ & $\begin{array}{c}\text { Group } C \\
(n=22)\end{array}$ & $\begin{array}{l}\text { Controls } \\
(n=100)\end{array}$ \\
\hline Smokers & 140 & 55 & - & 42 \\
Age (mean (SD, range) y) & $40 \cdot 3(6 \cdot 0,20-59)$ & $40 \cdot 0(8 \cdot 2,23-56)$ & $37 \cdot 3(6 \cdot 2,25-44)$ & $42 \cdot 9(5 \cdot 3,24-51)$ \\
Work duration (mean (SD, range) y) & $9 \cdot 5(5 \cdot 6,1-24)$ & $7 \cdot 4(5 \cdot 3,2-28)$ & $8 \cdot 1(5 \cdot 7,2-21)$ & $11 \cdot 7(7 \cdot 5,1-25)$ \\
\hline
\end{tabular}

among the studied groups during the past two years.

\section{Results and discussion}

The study showed 87 cases of dysplasia among the 334 miners in groups $\mathrm{A}, \mathrm{B}$, and $\mathrm{C}$ (frequency $0.26,95 \%$ CI $0 \cdot 21-0.31) v$ three cases among the 100 controls $(0.03,95 \% \mathrm{CI}$ $0 \cdot 007-0.077)$. Thus, the higher occurrence of dysplasia in exposed miners was significant $(P<0.0001)$.

The data in table 1 indicate similar distributions of age and underground work practice for exposed and not exposed groups-that is, the exposures to silica, dust, and other toxic inhalants (not $\mathrm{Rn}$ ) were expected to be similar. The stepwise logistic regression analysis showed the significance of exposure to $\mathrm{Rn}$ progeny $(P<0.0001)$ and smoking $(P=$ 0.0016). The underground work experience did not fit the criteria for significance. These results support the opinion that the prevalence of the frequency of dysplasia in the exposed group is probably related to the inhalation of Rn and Rn progeny.

In the model used, the risk of dysplasia was estimated as:

$$
\exp (\mathrm{z}) /(1+\exp (\mathrm{z})) \text {. }
$$

In this expression $z=-2.79+0.012$ WLM + $1.089 \mathrm{Sm}$, where smoking $(\mathrm{Sm})$ is treated as a dichotomous variable $(0=$ non-smoker, $1=$ smoker). The numerical coefficients for smoking (1.089), exposure in WLM $(0.012)$, and constant $(-2.79)$ are the maximum likelihood estimates derived by logistic regression. The analyses suggest an exposure-response relation, which was different for smokers and non-smokers (table 2).

The frequency of dysplasia for non-smokers at the lowest exposure (0-50 WLM) was not significantly above the controls, whereas for smokers the prevalence was significant $\left(\chi^{2}=5.91, P=0.015\right)$. In this lowest exposure subgroup the greater frequency of dysplasia in smokers over non-smokers was significant $(P=0.033)$. The results for the group exposed to 50-150 WLM showed similar frequency of dysplasia for smokers and non-smokers. The frequency of dysplasia for non-smokers in this high exposure subgroup was significantly above the controls $\alpha^{2}=$ $9 \cdot 83, P=0 \cdot 007)$. A greater frequency of dysplasia occurred in smokers than in non-smokers, but it was not significant $(P=0 \cdot 40)$. The frequency of dysplasia was further increased in the highest exposure group (>150 WLM) and the prevalence of dysplasia in the smokers $v$ the non-smokers was significant $(P=0.02)$.

The results in groups B and C (table 2) were considered in view of exposure-response relations derived for group $\mathrm{A}$. The results for group B did not conflict with those assessed by extrapolation of a range of exposures (2-70 WLM). The $95 \%$ CIs for group B were consistent with low (<50 WLM) and occupational (50-150 WLM) exposures.

With the information about the exposures of group C (range 2.5-346 WLM) and the logistic regression coefficients derived for group A, expected frequency of dysplasia for this group was estimated. The results showed that if group $C$ is considered as non-smokers the expected frequency of dysplasia is $0 \cdot 19$, but if group $\mathrm{C}$ is considered to consist of smokers the expected value is 0.35 . The observed frequency was $0.27 \quad(95 \%$ CI $0 \cdot 11-0.48)$ between both the expected frequencies (for smokers and non-smokers). Due to the broad CI the differences between observed and expected ratios for smokers and non-smokers were not significant. In general the results for groups $B$ and $C$ gave semiquantitative support to the exposure-response relation found for group A.

According to the results of our study, when the exposure was $>50$ WLM the risk of dysplasia was $>0 \cdot 1$ (non-smokers) and $>0 \cdot 25$ (smokers). Above $150 \mathrm{WLM}$ the risks were $>0.3$ and $>0.5$ respectively. These results indicated that the frequency of dysplasia may be used for a retrospective estimation of the range of exposures for groups with unavailable or very scarce data on radiation monitoring. This could be the case in parts of the third world.

Besides these benefits, some limitations

Table 2 Frequency of dysplasia by exposure

\begin{tabular}{|c|c|c|c|c|c|}
\hline \multirow[b]{2}{*}{ Group } & \multirow[b]{2}{*}{$\begin{array}{l}\text { Exposure } \\
\text { (WLM) }\end{array}$} & \multicolumn{2}{|c|}{ Non-smokers } & \multicolumn{2}{|l|}{ Smokers } \\
\hline & & $\begin{array}{l}\text { Dysplasial } \\
\text { total }\end{array}$ & $\begin{array}{l}\text { Frequency } \\
(95 \% \text { CI })\end{array}$ & $\begin{array}{l}\text { Dysplasial } \\
\text { total }\end{array}$ & $\begin{array}{l}\text { Frequency } \\
(95 \% C I)\end{array}$ \\
\hline $\begin{array}{l}\text { Group B } \\
\text { Group C } \\
\text { Controls }\end{array}$ & $\begin{array}{l}0-50 \\
50-150 \\
>150 \\
2-70 \\
2 \cdot 5-346\end{array}$ & $\begin{array}{l}2 / 45 \\
7 / 27 \\
8 / 21 \\
4 / 24 \\
\\
2 / 58\end{array}$ & $\begin{array}{l}0.044(0.007-0.132) \\
0.26(0.12-0.44) \\
0.38(0.19-0.59) \\
0.167(0.054-0.348)\end{array}$ & $\begin{array}{r}7 / 37 \\
26 / 77 \\
19 / 26 \\
8 / 55 \\
6 / 22 \\
1 / 42\end{array}$ & $\begin{array}{l}0.19(0.085-0.335) \\
0.34(0.24-0.45) \\
0.73(0.54-0.88) \\
0.145(0.069-0.255) \\
0.27(0.11-0.48) \\
0.024(0.001-0.10)\end{array}$ \\
\hline
\end{tabular}


have become obvious with this approach. The exposure-response relation was for active miners. Former miners could be unsuitable, because of a possible disappearance of dysplasia in a proportion of them, thus making the interpretation of the results unclear. In our cohort both smokers and non-smokers showed exposure-response relations, but the group of smokers showed relatively uniform smoking habits (about two thirds of them smoke one pack/day). This could not be expected in every case. Different smoking habits may result in different dysplasia outcomes. Therefore, it is our belief that the nonsmokers group gives a better opportunity for the retrospective exposure assessment. In either case, to avoid possible strong differences due to the different way of life, smoking habits, ${ }^{15}$ or individual sensitivity of miners in different areas of the world, a preliminary investigation of a group analogous to our group A may be necessary for reliability in such studies.

\section{Conclusion}

We conclude that exposure of underground miners to ${ }^{222} \mathrm{Rn}$ progeny results in a significantly increased frequency of squamous cell metaplasia. At the level of notable dysplasia, this frequency follows an exposure-response relation. Sputum cytology could be used for a retrospective assessment of the range of exposures for groups for which this range could not be assessed directly. In the arrangement of such studies the limitations of this approach should be recognised. Further investigations of metaplasia in miners are needed to clarify the exposure-response relation under different conditions.

1 Radford EP, St Clair Renard KG. Lung cancer in Swedish iron miners exposed to low doses of radon daughters. iron miners exposed to low doses

2 Sevc J, Kunz E, Tomasek L, Placek V, Horacek J. Cancer in man after exposure to Rn-daughters. Health Phys 1988 ; $54: 27-46$

3 Pershagen G, Akerblom G, Axelson O, Clavensjo B, Damber L, Desai G, et al. Residential radon exposure and lung cancer in Sweden. $N$ Engl $f$ Med 1994;330 159-64.

4 Saccomanno G, Archer VE, Auerbach O, Saunders RP, Brennan L. Development of carcinoma of the lung as reflected in exfoliated cells. Cancer 1974;33:256-70.

5 Kinsella DL Jr. Bronchial atypias: report of preliminary study correlating cytology with histology. Cancer 1959; study corre

6 Saccomanno G, Saunders RP, Klein MG, Archer VE, Brennan L. Cytology of the lung in reference to irritant, individual sensitivity and healing. Acta Cytol 1970;14: 377-81

7 Risse EKJ, Voijs PG, Van't Hof MA. Diagnostic significance of severe dysplasia in sputum cytology. Acta Cytol 1988;32:629-34.

8 Saccomanno G, Saunders RP, Archer VE, Auerbach O, Kushner M, Becker PA. Cancer of the lung: the cytology of sputum prior to the development of carcinoma. Acta of sputum prior to the $1965 ; 9: 413-23$.
Cytol

9 International Commission on Radiological Protection. Limits for inhalation of radon daughters by workers. Oxford: Pergamon Press, 1982. (ICRP Publication 32.)

10 Papanicolaou GN. A survey of actualities and potentialities of exfoliative cytology in cancer diagnosis. Ann Intern Med 1949;31:661-74.

11 Saccomanno G, Saunders RP, Ellis H, Archer V, Wood B, Beckler P. Concentration of carcinoma or atypical cells in sputum. Acta Cytol 1963;7:305-10.

12 Fulmer CD, Short JG, Allen A, Walker K. Proposed classification for bronchial epithelial cell abnormalities in the category of dyscariosis. Acta Cytol 1969;13:459-71.

13 Kelsey JL, Thompson WE, Evans AS. Methods in observa tional epidemiology. Oxford: Oxford University Press, tional

14 Hosmer DW, Lemeshow S. Applied logistic regression. New York: John Wiley, 1989.

15 Samet JM, Kutvirt DM, Waxweiler RJ, Key CR. Uranium mining and lung cancer in Navajo men. $N$ Engl $f \mathrm{Med}$ 1984;310:1481-4.

\section{Correspondence and editorials}

Occupational and Environmental Medicine welcomes correspondence relating to any of the material appearing in the journal. Results from preliminary or small scale studies may also be published in the correspondence column if this seems appropriate. Letters should be not more than 500 words in length and contain a minimum of references. Tables and figures should be kept to an absolute minimum. Letters are accepted on the understanding that they may be subject to editorial revision and shortening.

The journal also publishes editorials which are normally specially commissioned. The Editor welcomes suggestions regarding suitable topics; those wishing to submit an editorial, however, should do so only after discussion with the Editor. 